\title{
Sharing and the Democratic Form of Human Life
}

How to Reconstruct Peirce's Metaphysics of Agapasm, Rhetoric and the Interactional Basis of Democracy

Helmut Pape

\section{(2) OpenEdition}

1 Journals

\section{Electronic version}

URL: http://journals.openedition.org/ejpap/2096

DOI: 10.4000/ejpap.2096

ISSN: 2036-4091

\section{Publisher}

Associazione Pragma

\section{Electronic reference}

Helmut Pape, «Sharing and the Democratic Form of Human Life », European Journal of Pragmatism and American Philosophy [Online], XII-2 | 2020, Online since 14 December 2020, connection on 15 December 2020. URL : http://journals.openedition.org/ejpap/2096 ; DOI : https://doi.org/10.4000/ ejpap.2096

This text was automatically generated on 15 December 2020.

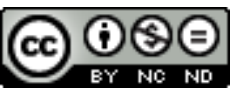

Author retains copyright and grants the European Journal of Pragmatism and American Philosophy right of first publication with the work simultaneously licensed under a Creative Commons AttributionNonCommercial-NoDerivatives 4.0 International License. 


\section{Sharing and the Democratic Form of Human Life}

How to Reconstruct Peirce's Metaphysics of Agapasm, Rhetoric and the Interactional Basis of Democracy

Helmut Pape

\section{AUTHOR'S NOTE}

I dedicate this paper to Jürgen Habermas. - I want to thank an anonymous referee for his/her insightful criticsm, comments and suggestions and A. Dymek, Bamberg for suggesting many corrections, additions and a new structure. - The third section overlaps with "Compulsions, Forces and Assertions. Peirce on the Semiotics of Rhetoric," a lecture presented in Helsinki, April 22, 2014 at the conference "Applying Peirce 2."

"A road is where humans left their traces." (Publilius Syrus, 1. century BC)

“Thus if the utterer says 'Fine day!' he does not dream of any possibility of the interpreter's

thinking of any mere desire for a fine day that a Finn of the North Cape might have entertained on April 19, 1776. He means, of course, to refer to the actual weather, then and there, where he and the interpreter are alike influenced by the fine weather, have it near the surface of their common consciousness."

(Peirce, Charles Sanders, from: MS 318, ${ }^{1} 1907$, in: The Essential Peirce, Vol. 2 (1893-1913), Bloomington/Indianapolis 1998, p. 407; quoted in what follows as EP 1 or 2 ) 


\section{Introduction: Reconstructing Aspects of Peirce's Thought}

1 This paper does not give an interpretation of Peirce's philosophy. It takes certain features of his thought as points of departure so as to reconstruct them in terms of a theory of sharing human life adapted from the German philosopher Rainer Marten.

2 Section I shows that the metaphysics of evolutionary agape love rests on a rhetoricalmethodological argument. The agapastic principle that love is the highest principle of evolution is reconstructed in terms of sharing relations and leads to a moral selection principle. This move implies that the moral cognitivist's interpretation ${ }^{2}$ of Peirce's ethics that moral development depends on truth, knowledge and inquiry alone is incomplete in its account of the role inquiry plays in the moral and social development of a person.

3 The core argument in Section II addresses in detail Peirce's rhetorical and semiotical analysis of assertion. It shows that in a pragmatically restricted sense sharing is crucial for Peirce's rhetorical analysis of assertion and that rhetorical arguments are present everywhere and from the beginning of his work: it is by no means limited to Peirce's late, unfinished explicit project, a general rhetoric as general semiotics third discipline - called "speculative," "formal," "universal" or simply "methodeutic" - for all types of interpretation. The reconstruction shows that assertoric semiosis involves existential relations of humans sharing each other's life and purposes. The rhetorical analysis explains how interacting with assertions via close, existential sharing is successfully achieved only when participating in situations with others is feasible. That is, the successful use of assertions depends on both, that experiences and purposes can be shared.

4 In Section III, a concept of sharing is developed that supports a neo-Peircean concept of democracy and allows a reconstruction of Peirce's rhetoric and agapasm. The crucial step is that equal mutual person-to-person relations are shared that are basic for sign use, inquiry, everyday social interactions and communication. Since agape-love and sympathy become efficient only in relational practices which guide the development of purposes, they are - in a democratic society - necessary to extend person-to-person relation to the political level. To see how sharing works the paper takes account of some of Peirce's anthropological and epistemic claims and the semiotics of the moral and social development of the self.

5 Section IV discusses the relation between economy and society, and democracy in particular, which (cf. Section I), Peirce addressed in his argument for agapasm. It is argued that a genuine sharing economy provides an alternative to the market economy and that the economy of sharing is a form of life that undergirds democratic social groups and societies. Genuine sharing, by enabling equality in the access to economic, moral and other opportunities allows homo sapiens to find its political realization in the communal life of some form of democracy. 


\section{Agapasm and Politics: Sentiment and the Contradiction between Capitalism and Democracy}

6 Today most political and social scientists agree that capitalism's practice and ideology of individual profit and unlimited economic growth is socially destructive. Because profit as an ideal that is supposed to give meaning to human life tends to destroy social relations, morality and democratic institutions. Peirce had something similar in mind when in 1893 he attacked the "philosophy of greed." His topic is not greed as an attitude of individuals but how in science and in western societies different sorts of purposes are ranked. Because when a society understands greed as the paradigmatic ideal or purpose this damages the moral and social structure of human relations. Peirce's 1893 prophecy that a complete break-down of the social structure in the US and other western societies would take place did not come true but is related to problems that are still with us:

The twentieth century, in its latter half, shall surely see the deluge-tempest burst upon the social order - to clear upon a world as deep in ruin as that greedphilosophy has long plunged it into guilt. (EP 1: 356; 6.292)

7 This gloomy prophecy rests on a rhetorical, methodological argument that attacks the way in which the conclusions of political economy are generalized into a claim about the order of all human purposes. The objection - which does not simply reject political economy or deny that greed may have an economic function - is that from theories in political economy no general theory evaluating all human purposes can be developed. It argues that it is a methodological error to assume that all human purposes have to be greed-like:

But the study of doctrines, themselves true, will often temporarily encourage generalizations extremely false, as the study of physics has encouraged necessitarianism. What I say, then, is that the great attention paid to economical questions during our century has induced an exaggeration of the beneficial effects of greed and of the unfortunate results of sentiment, until there has resulted a philosophy which comes unwittingly to this, that greed is the great agent in the elevation of the human race and in the evolution of the universe. (EP 1: 354; 6.292)

In granting priority to greed, an order of human purposes is excluded that does justice to naturally evolved purposes, which are based on emotions or "sentiment" between persons. Even Peirce's positive metaphysical claim, the principle of agapasm, rests on this methodological argument, because it implies a claim about the selection of purposes. Peirce argues that if an order of human purposes does justice to "sentiment" it will allow for a better social, moral and cultural evolution of human civilization. Therefore the principle of agapasm that love as agape is the highest moral principle for human evolution, is not just a strange metaphysical claim:

The movement of love is circular, at one and the same impulse projecting creations into independency and drawing them into harmony. This seems complicated when stated so; but it is fully summed up in the simple formula we call the Golden Rule. This does not, of course, say, Do everything possible to gratify the egoistic impulses of others, but it says, Sacrifice your own perfection to the perfectionment of your neighbor. (EP 1: 352, 6.288)

Later on, Peirce is very specific about the persons who are the subjects of agape-love:

Love is not directed to abstractions but to persons; not to persons we do not know, nor to numbers of people, but to our own dear ones, our family and neighbors. "Our 
neigbor," we remember is one who we live near, not locally perhaps but in life and feeling. (EP 1: 352, 6.288) gives priority to feelings insofar as they are "not locally" bound. That is to say, the relation of sympathy has priority over anything that actually takes place between two people. Interactively, here and now, shared life, from which all "not locally" bound sympathetic feelings have to start, contributes nothing to the emotion. But the "movement of love" may be reconstructed as a "method of love" that takes sharing another person's life in a pragmatically serious way giving priority to relations actually enacted by people. In this way, Peirce's claim that society is based on "the sympathetic connection with the collective people" (6.307) may be reconstructed by using a rhetorical argument: It is the actual, embodied sharing of both purposes and interaction that makes an account of common purposes and their selection possible (cf. EP 1: 354; 6.292). Agapasm, reconstructed in this way, becomes a claim about sharing purposes and actions interactively when choosing them. Indeed, the topic of this principle is the practice of human social and moral relations in general. By invoking the golden rule, it can be extended such that any two people, already sharing life, in choosing purposes and courses of action should take into account

1) that the choices of each should depend on the consequences they have for the other person sharing them, and

2) that everyone's choices should, if possible, aim at what is good (or bad) for every other person who will share them.

Precisely because Peirce talks about the perfection of another person in terms of "drawing into harmony," agape-love can be reconstructed as a selection principle: purposes are developed when people who share their finite life develop new, cooperatively enacted purposes with each other for the betterment of all involved. Agape-love, as a principle of selection for everyone involved in a shared relationship, entails that each person will, in her/his choices, better the other's life. This applies to those purposes that can only be realized in society. Interpreted as a method, agape-love thus chooses purposes which motivate shared actions and social relations for some common good that may govern the actual historical situation of living together. Reconstructed agapasm may be extended to provide an argument for how democracy is related to sharing as a form of human life.

Peirce does not discuss "democracy" and related political issues in his published and unpublished writings and it would be misleading to assume that Peirce's concepts imply some political philosophy. Agape-love, pure and simple, stands for "sympathetic connections," based only on sharing "ideas" with humans who are close, but for "nonlocal" reasons of sympathy. Even in those cases where a political meaning is implicit, such a reading is not intended. Take e.g. Peirce's notion of "agapastic or [...] socialistic ontology," ${ }^{4}$ or the concepts of a community of investigators and of the common consciousness required for semiosis. The case of "socialistic ontology" shows that his agapasm is a thesis only about emotional relations between humans only. These concepts are part of his theory of inquiry, logic or semiotics.

13

Even when, in "Dmesis," a short paper on criminal justice, Peirce addresses an issue of political philosophy by discussing the status and range of justice in society, he argues theologically and in terms of his metaphysics of agapasm: society is denied the right to punish criminals, because although society may protect itself against criminal action, it 
is, first of all, obliged to help, cure and resocialize the criminal by allowing for experiences which awake "the higher man" (Peirce) in her/him. Sharing is the practice which, by giving much equal "sympathetic" weight to all humans related interactively in a society or community, requires actual political and social processes in the choice of purposes. But to this end, only a democracy provides the free and equal space of development. Because only "if we can only enter into the spirit of Love, so as to see how it acts and to put our trust in it, then we shall be able to bring about a new stage of man's development," ${ }^{5}$ the execution of justice in a human society is justified. In this case it builds on and develops the ability of agapastic sympathy between human beings. That is, human social existence and morality depend on agapastic love in personal and inter-personal relations. And this in turn implies that "every individual merging his individuality in sympathy with his neighbors" (6.294) and that groups, institutions and even society depend on some sort of "sympathetic connection." But this already implies a concept of sympathy that Peirce did not have: For him, only those attitudes and relations that people have to each other because their sentiments tells them so are morally and politically relevant - in his evolutionary-metaphysical approach. But at least Peirce came to see that there is sort of a democratic "common sense" and experience, due to culturally well-entrenched feelings of sympathetic emotions about what is good and which might be shared by "all of us." The "sympathetic connection" approach to political issues describes a way of life which supports democracy only if "sympathetic connection" is reconstructed in terms of human interaction and cooperation in situations of everyday life. That is, a strong concept of sharing would subsume sympathetic connection as a special case of a close relation based on sharing.

Peirce's rhetorical, methodological argument against greed as a paradigmatic purpose already connects love's power as a method of purpose selection to semiotics and rhetoric. But reconstructing semiotics and rhetoric in terms of actual sharing relations will strengthen the connection and will imply a semiotic anthropology. This connection between semiotic anthropology, sharing of purposes and rhetoric needs a theoretical justification. Thus the next section will show that in the analysis of actual dialogical interactions, using assertions, semiotics and rhetoric have to resort to sharing.

\section{The Rhetoric of Assertion}

The subject matter of Peirce's comprehensive and anti-traditional account of a new rhetoric is all interactive sign-use: all the conditions, methods, rules and strategies of thought or interaction which generate or preserve meaningful interpretations. ${ }^{8}$ Pragmatism is thus a rhetorical theory, because it is a method for clarifying an assertion by translating and evaluating it according to the practical consequences that follow from it. Pragmatism deals with the systematic connection between the three parts of semiotics, speculative grammar (semiotic in the usual, narrow sense), critic (formal logic). Semiotics in a general sense, as a philosophical account of all sorts of representation, is complemented by a pragmatic account of methods, conditions and rules which in human communities allow us to develop practical consequences.

For Peirce's concept of persons and their relation it is important to keep in mind that in formal logic and semiotics (sometimes called "speculative grammar") no psychological concepts are used to understand signs. The interpretant of a sign is not a person but 
another sign interpreting a first one, a requirement which is dropped for the third, last part of semiotics, speculative rhetorics:

In coming to Speculative Rhetoric, after the main conceptions of logic have been well settled, there can be no serious objection to relaxing the severity of our rule of excluding psychological matter, observations of how we think, and the like. The regulation has served the end; why should it be allowed to hamper our endeavours to make methodeutic practically useful. $(2.107,1902)$

If speculative rhetoric is reconstructed to explain the interactive conditions of democratic politics, it has to account for how people think and act, that is, it has to study the different ways and conditions in which, in communities, people's approaches, interpretations and goals are shared. But for Peirce, engaging in a process of checking the truth claim of an assertion is the basic dynamic case in which experiences, language and purposes are shared. Therefore the rhetorical analysis of assertion is a study of the interactive, performative elements of the dialogical process to which assertions belong in order to show how sharing and communities are related.

This is because to assert a proposition is a rhetorical action: both believing and asserting a belief involves "an action that is related to our thought" (MS 599, 1902, \& in MS 499/499s, 1906). Yet logic and semiotics do not treat assertion as the fundamental structural model of semiotic form; their focus is upon argument and inferential relation. Rhetoric, however, studies the non-formal conditions of interpretation in language communities that enable people to utter and interpret signs. And assertion is the paradigmatic social act in using language in dialogue where at least two people interact. Therefore the rules and conditions that rhetoric looks for deal with what connects two positions, analogous to proposing vs. interpreting an argument. Of course, these positions are occupied by independently existing humans. But in using signs, humans become either an utterer or an interpreter of a sign. Both the existential independence and their systemic positions are rhetorical features: all logical forms, semiotic processes and relations operate on and presuppose at least this two-position model of interaction and the existential fact that these positions are occupied. The dialogue is the paradigm of language in use, because "it is not merely a fact of human Psychology, but a necessity of Logic, that every logical evolution of thought should be dialogic" $(4.551,1904)$. Peirce proposed various concepts for these dialogical positions, e.g. the Artifex of Nature and the interpreter of nature, author and interpreter, speaker and listener, graphist and grapheus, etc. ${ }^{9}$

\section{II.1. The Rhetoric of Attention and of Linguistic Experience in Validating Assertions}

19 Let us start with an obvious though often overlooked characteristic of signs and assertion. The first effect of uttered tokens is that the token is grasped as such. The utterance of an assertion is not just a physical effect on the interpreter: to perceive something as a sign is an initial semiotic activity. There has to be an interactive process, even if the token is only subconsciously attended to. At the level of subliminal attention, the assertion has to be already effective in a noticeable way. Of course, there is not much of a difference with the utterance of other signs. For example, Peirce points out that assertion and question share the same rhetorical property of arousing attention: 
An assertion has its modality, or measure of assurance, and a question generally involves as a part of it an assertion of emphatically low modality. In addition to that, it is intended to stimulate the hearer to make an answer. This is a rhetorical feature which needs no special grammatical form. If in wandering about the country, I wish to inquire the way to town, I can perfectly do so by assertion, without drawing upon the interrogative form of syntax. Thus I may say, "This road leads, perhaps, to the city. I wish to know what you think about it." The most suitable way of expressing a question would, from a logical point of view, seem to be by an interjection: "This road leads, perhaps, to the city, eh?" $(4.57,1893)$ might do a better job of information-gathering than an assertion. However, the other task performed is the capturing and focusing of attention of the hearer/interpreter. One assumption of a rhetorical account of assertion is that in order to understand how an assertion functions semiotically, rhetorical evidence is decisive in enabling the appropriate interpretative response on the part of the listener. Peirce's term to describe rhetorically effective features of signs (in written texts, dialogues) is "rhetorical evidence." Rhetorical evidence covers the arousal of a person's perceptual attention when he or she perceives that some e.g. acoustical or visual event is a sign. In the case of an acoustic utterance of a sentence, some perceptual and basic orientation processes will become rhetorical evidence. Because "we can directly observe what is familiar to our experience of assertions and seems to be inseparable from them" $(2.333,1896$, MS 787). Let us take as an example an utterance where someone sees a horse in the distance and, turning to the hearer, says:

(1) "There is a brown horse over there."

21 To grasp that there is a sign you have to understand the uttered token and what it might be about. In terms of Peirce's semiotics, we are able to understand what the sign's possible object, i.e. its "immediate object," might be like. This may take place subliminally and depends on a cognitive process that introduces the unifying idea of some single object of sorts. This immediate object remains "unexpressed by the sign" (MS 318) but its activation allows us to react to and select features of the actual or possible situations. This entails a) the interpreter's ability to understand the assertion (1) as the singling out of something as a brown horsey object; b) the "we" in Peirce's thesis that "we can directly observe what is familiar" implies some "direct observation" without implying that this depends on subjective observation only. That which is inseparably linked to assertion in the rhetorical evidence depends on a relational approach, which is composed of actual, i.e. performatively shared modes of comprehension and interpretation. A rhetorical account of assertion must explain its semantic and epistemic role: there are familiar, iconically and indexically guided perceptual reactions in semiotic situations which allow for a direct, shared understanding and access to situations where linguistic assertions can be checked. Such a concept of direct, non-linguistic access combined with a division of labor between language and shared non-linguistic epistemic activities is the starting point of rhetorical analysis:

It is requisite then, in order to show what we are talking or writing about, to put the hearer's or reader's mind into real, active connection with the concatenation of experience or of fiction with which we are dealing, and, further, to draw his attention to, and identify, a certain number of particular points in such concatenation. $(3.419,1896)$ 
No "sympathetic connetion" or "sentiment" is needed: what constitutes a "connection" to experience for those involved in a dialogue opened by an assertion are both cognitive features and direct situational observations that can be shared in person-toperson relations and contribute to the use of assertions. The observation of the sign itself $^{10}$ is the starting point: the act of uttering a proposition assertively lets the listener grasp those relations that subsist between people, objects, circumstances in the situation in which it is used and to which it refers. It prompts the interpreter to access the observation by grasping, sometimes only imaginatively, situations in which the assertion might be validated.

\title{
II.2. Sharing the Speaker's Compelling Experience
}

\author{
"[...] an act of assertion supposes that, a \\ proposition being formulated, a person performs \\ an act which renders him liable to the penalties \\ of the social law (or, at any rate, those of the \\ moral law) in case it should not be true, unless he \\ has a definite and sufficient excuse [...]" \\ $(2.315,1903)$ \\ "Unsere Rede erhält durch unsre \\ übrigen Handlungen ihren Sinn."11 \\ (Ludwig Wittgenstein, "Über Gewissheit," \\ Frankfurt 1970, § 228, S. 63)
}

Stand-alone assertions do not belong to an argument. Sometimes they are used as commands to accept a certain proposition because somebody - an authority, a manager, a celebrity - says so. But in this case the content whose truth the assertion claims is not checked. Of course, there are always relations and actions which both the speaker and interpreter have to engage in to interact by means of assertions. Both have to do something and have to grasp situational relations to make and interpret an assertion successfully. The rhetoric of assertion shows that only due to rhetorical evidence do both utterer and interpreter accept that the truth of the assertion can be understood and checked. Meaningful propositions are therefore to be expressed by assertions referring to some situation where the interpreter may perform the experience that may validate the assertion:

Thus every kind of proposition is either meaningless or has a real Secondness as its object. This is a fact that every reader of philosophy should constantly bear in mind, translating every abstractly expressed proposition into its precise meaning in reference to an individual experience. $(2.315,1903)$

That is to say, a proposition is meaningful, if it can be checked in a situation in which some evidence for it is accessible for some interpreter too. There is an experience of an objective relation which compels the speaker to make the assertion. This is the accessible "individual experience" supplying rhetorical evidence for the assertion. The speaker, by the utterance of the assertion, wants to pass on this experiential compulsion. Because it is shared compelling evidence - "yes, I can see the brown horse over there" - that induces someone to accept $p$. It is not a logically necessary move, even if there is situational evidence shared and relevant for an assertion. 

assertion find themselves in is analogous to an argument: the interpreter is able to interpret the assertion correctly if both share the same evidence and he or she accepts the premises as well as the move from them to the assertion. To assert a proposition is a move subject to rhetorical rules embodied in dialogical practice. Becoming convinced in the first place presupposes that in a dialogue the partners accept that what is commonly shared determines an assertion's validity and truth. Rhetoric, in asking "what conditions a sign must conform to, in order to be pertinent to the purpose" (NEM IV: 62) and in explaining the practice of inquiry and interpretation, has to study the structure of shared purposes. Surely, all signs, in aiming to represent some object, have a teleological structure and, in science, truth is the teleos of the community of investigators. Because "a science [...] is a deliberate course of inquiry. As such, it is animated by a purpose." (MS 1343, 00019). For Peirce, science is a way of life, requiring common purposes. In 1902, in MS 1343 on the classification of the sciences, Peirce describes science as a "mode of life that seeks cooperation" (0009). Consequently, the "principles of science" have a teleological basis in purposes that also govern close cooperation. In the case of rhetoric this means that every use of signs in dialogue (particularly the use of assertions) tacitly assumes that the utterance by its author and its interpretation by its hearer/reader share a purpose that guides their cooperation in accepting its interpretation.

using a token of some specific system of signs, e.g. the German language, the author provides evidence that he or she belongs to a specific community of cooperative signuse: there is a tacit social identification involved in it. One of the cooperative purposes of assertions in science and everyday discourse is the well-known purpose of finding out whether the asserted fact is true or is interesting. But for interpretations of assertions to be rhetorically adequate and rational the interpreter has to agree or disagree relative to compulsions shared by both the author and interpreter. In 1896, in MS 787, Peirce proposes an analysis of assertion in rhetorical and grammatical terms:

The assertion consists in the furnishing of evidence by the speaker to the listener that the speaker believes something, that is, finds a certain idea to be definitively compulsory on a certain occasion. There ought, therefore, to be three parts in every assertion, a sign of the occasion of the compulsion, a sign of the enforced idea, and a sign evidential of the compulsion affecting the speaker in so far as he identifies himself with the scientific intelligence. (2.336)

The three aspects of the assertion's force together make up its evidential effect. When people interpret an assertion as true, they do so for the following reasons:

(1) Because of the subject term they are able to connect it to some compulsory situation (Peirce: occasion ${ }^{12}$ );

(2) because of the predicate term they understand that there is some shared qualitative content (Peirce: idea) applicable to this same situation;

and

(3) because the interpreter as well as the speaker recognize that there is "scientific" evidential relevance in the asserted connection between subject and predicate.

28 (1) and (2) describe how the asserted predicative content is tied to compelling relations the interpreter is able to access, e.g. features of some perceptual situation. These compelling relations are two-place and they subsist only if the relata are actually present. They are what Peirce calls "existential relations." Requiring their presence or accessibility for a correct interpretation of an assertion decides whether the validation 
of assertions will work or not. Because it connects contingent features of the situation of utterance of the assertion - to which the token used belongs - with those cognitive, practical and experiential processes the interpreter has to go through to understand why some situation is represented in the assertion as compelling:

Because compulsion is essentially hic et nunc, the occasion of the compulsion can only be represented to the listener by compelling him to have experience of that same occasion. Hence it is requisite that there should be a kind of sign which shall act dynamically upon the hearer's attention and direct it to a special object or occasion. Such a sign I call an Index. It is true that there may, instead of a simple sign of this kind, be a precept describing how the listener is to act in order to gain the occasion of experience to which the assertion relates. But since this precept tells him how he is to act, and since acting and being acted on are one and the same, and thus action is also hic et nunc, the precept must itself employ an Index or Indices. That to which the index directs attention may be called the subject of the assertion. (2.336)

The interpretation of the utterance creates the sameness of situated, "occasioned" experience and is produced by sign-relative mental actions. ${ }^{13}$ This gives the assertion the status of an offer or challenge: an assertion directs, invites the interpreter to enter into experiential contact with some relevant compelling occasion which, according to rhetorical evidence conveyed by the assertion, is decisive to verifying its validity. On the one hand an assertion is an invitation, suggestion or proposal by the author for an interpreter to share what is asserted as objective and true. The speaker invites the listener (interpreter) to produce an interpretation, by using his or her own practical and cognitive activities to verify its validity. Of course, assertions, just like other suggestions, can be refused or ignored: they are fragile and do not force anybody. But if an assertion is to be evaluated adequately, the interpreter has to accept it at least as a proposal. Because only in this case can the truth claim of the assertion be accessed: the interpreter has to experience the same compulsion that led the author to formulate the assertion.

The third condition involves a strong, metaphysical claim: there has to be some "evidence" that the speaker made and the interpreter has to acknowledge the assertion because he or she identifies with "scientific intelligence." What is at stake here is Peirce's account of truth as the object of an (with respect to time and all intelligent beings) unlimited community of inquiry. But if it is restricted to an actual community in which sharing relations between humans subsist during their life times, a different explanation emerges: to verify the truth of an assertion in a reliable way is open for everybody, because an open range of shared accessibility of the experience supporting the validity of the assertion is to be granted. Only those assertions can be true which rely on experiences that can be accessed by anybody who is willing and able to fulfil the necessary conditions for grasping and judging them. This is the normative meaning of "scientific intelligence," which prevents that e.g. some specific group of people would be arbitrarily excluded from sharing an asserted experience and interpreting an assertion. All those people/beings able to gain the epistemic, knowledge-based access to relevant experience may join in: the community of scientific intelligence is open for all; it only requires the willingness and ability to correct reactions, beliefs and attitudes through experience. But all these possible corrections of asserted beliefs require the sharing of experience as a starting point for cooperation within a community. This is Peirce's claim in 1902: "But science being essentially a mode of life that seeks cooperation, the unit science must, apparently, be fit to be pursued by a number of 
inquirers." (MS 1343, p. 0009, Classification of the Sciences). Experience will count as rhetorical evidence for an assertion only if it is at least potentially accessible for a community of inquirers. Nobody asserting a proposition may claim that it is true only relative to his/her individual experience/imagination and cannot be shared by others. Together, the three requirements describe how humans living contemporaneously are connected by the strategic rhetorical interplay of assertoric dialogues: In uttering an assertion, the speaker/author implicitly assures all listeners/readers that the circumstances of the evidence validating the assertion are accessible in the time of their life as situations in which they have occasion sharing experiences relevant for understanding the assertion.

The third condition of 2.336, the identification with every scientific intelligence, demands that we have trust in the experiential accessibility of assertions. If we combine this condition of assertions with the requirement of sharing of situational compulsions, we arrive at two conditions:

i. an assertion should capture the attention of the interpreter who will have to follow it as a suggestion that there really is something worthwhile ${ }^{14}$ which the assertion addressed to him/her will help him/her to find out;

ii. it requires a move or cognitive activity guided by the uttered assertion ${ }^{15}$ because of this interaction. It captures the attention of the interpreter, stimulating him/her to imagine, perceive and act appropriately.

The subject matter of rhetoric is all the rules, strategies, habits or moves taking place between people engaged with each other, sharing a common interest, goal or purpose. Rhetorically speaking checking what an assertion claims depends on the cooperation of people engaged in an interpretative process bound to the accessibility of experiences that can be shared.

\section{II.3. From Common Experience to Rhetorical Evidence}

Peirce argues as an anti-psychological externalist: we do not have to share the same material quality of feeling or sensation to share some experience. In rhetorical analysis, qualities of feeling have an interactional, strategic function. That is to say, a person engaged in a dialogue may appeal to or look for a relational value in reaction to some utterance. It is shared rhetorical evidence that provides the basis even for formal arguments:

For the deductions, or quasi-predictions, from theory having been made, it is requisite to turn to the rhetorical evidence and see whether or not they are verified by observation. If we find them to be so, not only does the analysis of assertion gain evidence of being completely rounded, but the theory of truth is rendered more probable. $(2.333,1896$, MS 787$)$

Experiential evidence becomes rhetorical evidence only if it can be accessed and used by other sign-users in a community to verify whether the assertion is true or not. This may be called Peirce's Common Sense-Account of rhetorical evidence: common, shareable and familiar experiences are suitable as rhetorical evidence, allowing the interpreter to grasp assertions directly. Invoking common, shareable, but unexpressed experience is traditionally called "rhetorical argumentation." By relying on a suppressed premise it is classified as an incomplete argument or enthymene. Peirce does not accept this rejection of rhetorical argumentation. For him, speculative rhetoric may give an account of the conditions of interpretability that consists in 
rhetorical arguments invoking the conditions, rules for common, shared experience and relations which cannot be expressed as premises. For example, when the dialogical participants in the situation of the utterance of an assertion are already present in a situation to which the assertion refers, this implicit condition cannot be made explicit. But strategic rules of interaction are able capture these conditions: they assume in various ways how and when for everybody taking part in a dialogue some evidential access to relevant experiences is required to understand and validate assertions. A rhetorical argumentation will make explicit these contingent possibilities from which specific rhetorical evidence might be accessed. ${ }^{16}$ Whereas deductive inference draws necessary consequences from premises, arguing from rhetorical evidence concerns the range and scope of the dialogical process embodying the argument. It invokes e.g. interactional moves based on the possible observational, motor-sensory or epistemic activity of the interpreter.

\section{II.4. The Rhetorical Account of Assertion: Conclusions}

Propositions in arguments and assertions in dialogues serve an analogous logical function. When Peirce characterizes propositions as truncated arguments or inferential processes, this describes assertions too. Because characteristic of assertions is that "a proposition is nothing more nor less than an argumentation whose propositions have had their assertiveness removed, just as a term is a proposition whose subjects have had their denotative force removed" $(2.356,1896)$. When viewed rhetorically, individual, isolated assertions are truncated dialogues. Only a response to them is missing. A rhetorical analysis of signs (assertions, concepts, incomplete conversations) will explain them in terms of models for a successful strategy of argumentative or interactional exchange. These models describe how some signs might be used as moves initiating and guiding successful dialogues or other ways of cooperation. The rhetorical power of signs is explained by describing how they are uttered by someone and perceived as being uttered by someone who wants someone else to react to them, accept and validate them, given some shared purpose. The sequence of perceptions and actions with signs and their interpretation will in these interactional moves function analogously to the dialogical structure of an argument.

Therefore one conclusion is that just as a proposition is related to and is interpreted in an inferential process, an assertion is a semiotic device related to and interpreted in a dialogue that needs both a purpose which author and interpreter in the dialogue share and a community to which the two parties are related. This is how they handle the evidence for the assertion they share.

\section{Sharing: The Connection between Semiotics and Moral Anthropology}

In the last two decades in biology, anthropology, psychology and the social sciences a new paradigm for explaining the uniqueness of humans and their societies has emerged that argues that the enormous evolutionary success of human beings is due to the power of the complex social relations homo sapiens sapiens is able to build up to each other. ${ }^{17}$ The crucial hypothesis of this paper is that, for humans, sharing each other's life is an unavoidable element for other more complex social, cultural and political 
relations, and acts as their necessary starting- and end-point. For this reason, sharing can also be called "existential": it is the only existential relation, created at a contingent time and place in which one human may engage with another human, both of them preconsciously experiencing each other as human beings. Relations of sharing between humans are fundamental because the equality of being human is established in a preconscious, purely interactive way. Because in sharing, humans mutually grasp and react to each other as being human. For this, no explicit recognition, no norms of reciprocal actions e.g. working for pay or exchanging gifts of equal value (cf. section IV) are necessary. That is to say, sharing is the most basic humanly human relation: it enables human life to go on under the most unlikely circumstances; it operates without requiring that other, more demanding relations such as shared intentions or moral relations such as altruism are already in place. This is the reason why sharing may be used to reconstruct sympathy and agape-love in terms of fundamental relations of sharing.

The concept of sharing captures a pragmatic interactional and contingent relation between humans developing purposes in contingent moment of the life they share as comtemporaries. The German philosopher Rainer Marten's concept of sharing one another's life, "Lebensteilung," describes what takes place in those finite moments of close mutual, interactive exchange between humans already thereby recognizing each other in their present position in each other's life. Lebensteilung ties human life and abilities to the contingent mutually cognitive, positional, actively produced relations of close person-to-person interactions. Lebensteilung is altogether practical, performative: it consists in close mutually grasped events of contact performed by touch, looks, words, noises and present positions taken.

It is surely a simple fact that it takes a man and a woman to produce a baby and that this baby will flourish and become a socially competent human being only by living in close contact not only with his/her parents but with other people, whether family or not. ${ }^{18}$ This highlights the way in which all those momentary experiences between humans build up a sequence of shared events: they are so many opportunities, cases of "kairos," in which the child and its parents are part of finite relations of contact, of touch and looks. We discover our own human self by living these moments as shared: I am human, just like those others I am in contact with. These face-to-face, skin-to-skin interactional co-presences are necessary to allow the self to grasp his/her own position. ${ }^{19}$ This universally contingent feature of being human is irreducible to something that happens to isolated individuals. ${ }^{20}$

Marten's account of sharing one's life and the notion of token-indexicality in Peirce's semiotics (in the rhetorical analysis of assertion in Section II) both exemplify the eventbound practice of shared existence. Peirce argues time and again (cf. the 2nd motto of this paper) that we can only communicate by taking present but unexpressed commonly shared relations for granted. The co-presence of what is said and the moment in which it is said can never completely be turned into something said explicitly. Analogously, Marten points out that sharing one's life is in place well before - independently of, but enabling of - consciousness and language and the development of moral abilities.

41 Of course, sharing the life of somebody is what happens between humans everyday, constantly, for all those who are alive at the same time and are in contact with one another. It happens unnoticed, unattended: it does not require thought, intentions or 
actions. Sharing takes place immediately as soon as two people attend to and grasp one another as humans, e.g. by looking, touching each other. Sharing another human's life, has already been performed as soon as signs are used, perceived and interpreted. It is what has taken place "then and there, where she/he [the author] and the interpreter are alike influenced" and may result in what Peirce calls "common consciousness" (MS 318 , 1905). Sharing involves simply a first cognitive grasp, the understanding and ongoing development of signs as token-entities and is true for any semiotic move, regardless of whether it is the mere grasping of a token of a linguistic sign, gesture or natural sign.

Section II showed how the rhetorical dynamics of assertion depends on the shared experience of using signs. The only place where for Peirce genuine sharing takes place and on which the interpretation of assertion depends are the relations which indexical tokens signify:

An index has nothing to do with meanings; it has to bring the hearer to share the experience of the speaker by showing what he is talking about. The words this and that are indicative words. They apply to different things every time they occur. (4.56)

Persons only "share" via an indexical token that activates what they have access to. For Peirce, however, this sharing is not connected with the agape driven and perfected development of shared purposes. One reason for this is Peirce's metaphysical, abstract concept of persons, selves and sympathy. As shown in Section I, there is no place for existential sharing, because only agape's sympathetic connection between persons and not existential sharing constitutes agapastic sympathy. This neglect of an account of existential sharing is the result of, among other factors, an abstract, metaphysically generalized concept of a person. Peirce's account of a person is, on the one hand, reasonable in refusing individualism. It implies a sort of Anti-Nietzeschean view, stressing the limits of the powers and possibilities of the individual. Clearly, a person is not an individual in the logical sense. ${ }^{21}$ But on the other hand, the person, the self via agape sympathy, is detached from the effects of existential sharing in space and time by a complex law-and-habit-generated sign process which is guided by agape sympathy. The anthropological thesis that "man is a sign," from around 1868, understands humans as law-like, habit- and interpretation-governed entities developing in communities of interpretation to which they belong. Later on, between 1892 and 1905, this thesis is supplemented by a thesis about the dialogical, rhetorical nature of human personality and understands social groups or even societies as persons:

Two things here are all-important to assure oneself of and to remember. The first is that a person is not absolutely an individual. His thoughts are what he is "saying to himself," that is, is saying to that other self that is just coming into life in the flow of time. When one reasons, it is that critical self that one is trying to persuade; and all thought whatsoever is a sign, and is mostly of the nature of language. The second thing to remember is that the man's circle of society (however widely or narrowly this phrase may be understood), is a sort of loosely compacted person, in some respects of higher rank than the person of an individual organism. (5.421, 1905)

Preconscious comprehensions are crucial for Peirce's semiotics and his agapasm. Uttering and perceiving the sign's material, like feeling agapastic sympathy take their start from what is performed and experienced preconsciously. In fact, it is a distinctive feature of Peirce's semiotics that all indexical signs have to be shared by preconscious perceptual reactions (cf. 4.56), which are triggered by the contingent material quality 
of the sign itself, by its being a specific quali- and sin-sign, a token of some type. Peirce's semiotics is the first account that integrates systematically the contingency of preconscious perceptive reactions to the sign's material existence. This approach is backed up by his experimental findings in the psychology of perception: In "Small Differences of Sensation," ${ }^{22}$ he and J.Jastrow proved that judgments about preconscious perception of weight differences are reliable to a statistically highly significant degree. Later on, in a number of other papers, e.g. "Telepathy and Pereption" (MS 881, 1903), he builds on these results and argues that in practical matters, humans rely, without knowing it, on preconscious perceptions in understanding their surroundings. But what Peirce did not take into account is that pre-conscious perceptions are necessary for becoming and staying alive as a human being. And only sharing captures for the semiotics of assertive, indexical communication the preconscious contact relations important for deciding what relations and facts are present. This neglect has ethical and political consequences, because existential relations between people are left out, as if sharing is no part of the account.

\section{III.1. Becoming Oneself by Being Related to Others}

According to Peirce's externalism ${ }^{23}$ what happens in the mind and how it develops is best explained by invoking external facts. But his agapasm has no place for external facts about the existential relation of human to other humans. Humans are genetically disposed to learn intuitively and performatively to share ways to agree, to cooperate ${ }^{24}$ and to simulate each other. These shared ways are habits of perception, reaction, action and thought. Most of these are multi-form, relational features, including nonverbal habits of spontaneous reactions, looks, gestures, linguistic performances and are to be experienced in close person-to-person exchanges. By acquiring habits in this way, including the "fortuitous variations of our actions" (6.86), human beings develop a self, understanding itself as positioned in relation to other humans. That is, the self and the other share rules and strategies. They take up and vary what is performed and embodied in the human neighborhood as their point of departure. The development of the self is never complete: the tie to interaction at the very moment of encounter with other people and the "fortuitous variations of our actions" always remains effective.

Peirce's notion of semiotic autonomy of a person and his externalism reconstructed in terms of sharing makes it possible that the self develops moral abilities by grasping its position in close relations to others. This involves the ability to develop out of the sharing relations one has lived through by cognitive layers of self-control, tied to sequences of interactions. That is to say, self-control ${ }^{25}$ of thought and habits of action is an ability from which self-controlled moral habits emerge and moral rules and principles arise:

When a man trains himself, thus controlling control, he must have some moral rule in view, however special and irrational it may be. But next he may undertake to improve this rule; that is, to exercise a control over his control of control. To do this he must have in view something higher than an irrational rule. He must have some sort of moral principle. $(5.533,1905)$

Because of the experience of relations to other selves the logical self becomes autonomous and capable of moral self-control and relating freely, with "subjective generality" (MS 330, 1906), to other people. Peirce's account of the self may thus be 
reconstructed as a kind of moral self-control that is embodied in and is relative to the individual's position in a community of person-to-person interactions. ${ }^{26}$ This practical participation in habits is the sort of interaction which can be rational and wellreasoned as well as spontaneous and without any reasoning involved. However, in both cases it requires that one has experienced situational sharing. Peirce's thesis that a person is a complex, developing teleological system implies that living as a person is possible only if he or she is free to develop or choose ideals, values or ends. Because in the case of personality this teleology is more than a mere purposive pursuit of a predeterminate end; it is a developmental teleology. "[...] Were the ends of a person already explicit, there would be no room for development, for growth, for life." (6.156f, 1892).

But there would be no possibility for humans to develop their life together without developing common purposes. The two claims, "man is a sign having purposes and experiences in common with each other" and "man is a developing system of purposes" complement each other: human individuals may each develop their own purposes and values and at the same time do so in a way that includes the other. In education and in daily life the cultural traditions of the society one lives in, the social environment in which one is born and raised, convey values. If individuals are able to live a human life in close contact with others, to develop new, different ends and purposes, humans use close interactional relations to adapt and transform their ends. For this reason, the developmental teleology is a self- and other-developmental process at the same time. Reflective self-control's interpretation of purposes and values may, for example, dialogically establish comparative relations between different ends and help to establish an evaluative relation to the purposes of others. This is the way to develop ends, in life's finite moments, by actively sharing life with other people in close encounters.

\title{
IV. Developing Means and Ends: The Rhetoric of Sharing Life in a Democracy
}

\author{
"[...] the task of democracy is forever that of \\ creation of a freer and more humane experience \\ in which all share and to which all contribute."
}

(Dewey 1936: 230)

The rhetorical account of the conditions for the interpretation of assertions turned out to rest on a shared experiential access to the situation, to the topic of communication, to the people addressed and to the possible communities one wants to belong to. Furthermore, Section I reconstructed agape-love as a selective strategy that picks out purposes that are sympathetically shared in a common development of individual life and interactions. To work for humans in the finite time of their life, sharing-based processes of exchange, communication and cooperation are needed so that democratic participation in politics and social life may develop in practice. Rainer Marten's conception of shared human existence shows how democracy may be supported by practical, close person-to-person interactions which allows humans to develop trusting and conscientious relations to other persons. Marten's approach is pragmatic: it is the actual finite and fortuitous relations between persons in the existential setting of sharing on which the flourishing of human life in a democracy depends. Because it is in 
terms of the success of direct, close contact (e.g. eye to eye) and dialogues that Marten's "humanly human" theory of the self understands moral and political processes. And it can in turn give us an account of conscience that may integrate Peirce's account of it as a self-critical way of dealing with sentiment's moral intuitions. This account applies to humans encountering, cooperating and confronting each other in the finite moments of their life. Because relations of sharing, e.g. transferring authority, power and trust to politicians in parliament and in government, are semiotically extended ways of sharing their life and constitute the interpersonal exchanges for sharing in a democratic political system. ${ }^{27}$

50 On the other hand, Peirce's agape-love reconstructed as sharing and his rhetorical approach to assertoric interaction supports a pragmatic moral anthropology. A rhetoric of democratic processes integrates the practical equality of positions for these person-to-person relations into the social and political conditions for developing democracy, because the rhetoric of assertion already requires equal access and possibilities for everybody concerned. This equality in the open development of life and purposes is a condition that can only be realized in a democracy: every individual's moral and political beliefs, developing aims, purposes and political strategies are allowed for, if they can be shared. Because only in a democracy are all forms of active participation in the development of community life ultimately possible. This equality of interaction and development in the form of daily life and in politics can be grounded in the reconstruction of Peirce's speculative rhetoric of assertion, if it is understood as involving equal sharing as a basis from which participatory, cooperative political practice develops. Because, as has been shown, already the rhetorical practice of assertion, in requiring the identification of the individual with a community of "scientific intelligence," can be boiled down to requiring an equality in sharing commonly accessible experiences.

\section{IV.1. The Economy of Sharing: Democracy and Living Together}

51 Today in many western societies, e.g. in Germany, some new economic practices of sharing are developing. The so-called "tables" (Tafel) provide free food, clothes, etc. from super-markets and from production facilities for people in need. This distributing of goods is, e.g. regulated by certain legal conditions: You have to prove that you are a low-income person to receive them. "Table-sharing" is neither a practice of marketeconomy nor of gift economy, nor does it come close to the equality of an economic variant of existential sharing between humans. For existential sharing to take place it would be enough for somebody to show up, for others to understand that he or she is present to receive all the food, clothes and other necessities for his or her life.

Today in almost all human societies on earth, market or state capitalism excludes an economy of sharing and exploits humans and natural resources. But the present situation is a historical, contingent one. It will likely end soon because of climate change, gross economic inequalities, depletion of natural resources and the extinction of millions of natural species will destroy the material conditions of world capitalism's unlimited growth. And the alternative - existential economic sharing - has been practiced all through the ages. The anthropologist Thomas Widlok, ${ }^{28}$ arguing on the basis of studies in Africa and South-America, has shown that in some cases the economy of existential sharing is still alive: there are hunter-gatherer societies 
interacting in relations of sharing, based on humans beings existentially related on equal terms. Through true sharing people are able to distribute goods, resources and work without invoking a system of market or gift exchange. Widlok develops his argument both theoretically and empirically from field studies of these huntergatherer-societies. In fact he performed some of these field studies himself. He shows that what is at stake in existential sharing with somebody is the enacting of an equality of self with others. The physical presence of a person alone is not decisive by itself: the other person has to be perceived and it has to be recognized that his or her presence is an active and persistent one, as a human being and only then does it lead, e.g. to sharing of food. Widlok provides photographic evidence for food sharing that comes to pass because a person "hangs around waiting for a share" of a meal. He argues that copresence acts as a sign, in this very moment of the other's cooking a meal, so that people understand each other as part of each other's life. Widlok points out that "physical and temporal co-presence are not enough, it is practical presence that needs to be established. Practical presence is presence that is recognized by both parties in the encounter." (Ibid.: 72).

Therefore in sharing economies the experiential grasp and status of human beings for each other is that they are alive and existentially related. Widlok shows that sharing relations are forms of direct, close and equal participation. Genuine sharing of health care and the "alloparental" care for children, food, warmth, etc. is performed by treating another human as part of the same situation or relation one finds oneself in. For this to happen no reciprocity of actions, gifts, shared intentionality or comparison of the value of what is to be shared for humans to interact is necessary. In such an economy of sharing, the equality of positions of each interacting human is an existential one: to everybody existing at some time of his or her life by being related to others, the same equal moral status and relational position is allocated.

In contrast, in every variety of market-economy as well as in economies of giftexchange the equality of value of the exchanged goods or actions is assumed in each economic interaction; ensuring value equality, accounting for reciprocal equality of value, in every economic transaction, is indispensible. This reciprocity of market and gift exchange is possible only by comparing and thereby understanding and reducing humans, as Marx pointed out, in their relation to each other to their contributions in terms of some standard of value, e.g. money. This requirement excludes the possibility that food is given to someone just because he or she "is around": relational equality, existential sharing and conscience are ruled out. These economic exchanges therefore not only exclude but even destroy relations of sharing one's life with each other ${ }^{29}$ If it is only the equivalence of economic value that counts, the mere fact that humans recognize each other as being human, and that they share the time and place of their life, is completely irrelevant in economic terms, regardless of how poor, hungry, needful one or the other human being is. That is to say, it is impossible in a market economy for economic interactions to take place by true sharing. ${ }^{30}$ If there still are some close human relations based on sharing sympathy, friendship or empathy, the introduction of reciprocal value to them by putting a price on them tends to destroy these sharing-based relations. ${ }^{31}$

In contrast, for existential sharing to obtain between people, grasping the presence of another person as a human being is sufficient to allow for acts of "Lebensteilung" involving both parties. Because existential sharing implies that human beings 
experience and address each other such that one is included by the other as this person who is here in this place now - e.g. drinking, eating, dancing. Widlok points out: "Instead of the obligations to give, to receive and to return, the ethnography of sharing suggests a pattern of opportunities to ask, to respond and to renounce." (2017: xvii).

In sum, a basic feature of a way of life that allows for a democratic human culture and economy are non-reciprocal techniques that rely on present relations between persons, objects and resources. This is to say, being in relation to one another is part of the human predicament, of what determines that homo sapiens sapiens remain human beings capable of living their lives together and engaging in moral and political processes that take care of the life and purposes of the humans involved. Democracy becomes real if, in a community on the person-to-person level as well as on the level of group or society, social and political interactions are based on and neither destroy nor exclude ways of existentially sharing life. Because if sharing is the practice which, by giving equal "sympathetic" weight to all human beings related interactively in a society or community, it will allow selecting purposes in political and social processes in a way that respects and intagrates everyone involved.

\section{BIBLIOGRAPHY}

ARIELY Dan, (2008), Predictably Irrational, New York, Harper-Collins.

BLAFFER HRDY Sarah, (1999), Mother Nature: Maternal Instincts and How They Shape the Human Species, New York, Ballantine Books.

BLAFFER HRDY Sarah, (2009), Mothers and Others: The Evolutionary Origins of Mutual Understanding, Cambridge, MA., Harvard University Press.

HARARI Yuval Noah, (2014), Sapiens. A Brief History of Humankind, London, Harvill Secker, Random House.

JäGER Wolfgang (ed.), (1994), Republik und Dritte Welt: Festschrift für Dieter Oberndörfer zum 65. Geburtstag, Paderborn, Schöningh.

MARTEN Rainer, (1988), Der menschliche Mensch: Abschied vom utopischen Denken, Paderborn, Schöningh.

MARTEN Rainer, (1993), Lebenskunst, München, Wilhelm Fink Verlag.

MARTEN Rainer, (1994), "Politische Lebensteilung. Der Gedanke des geteilten Lebens," in Wolfgang

Jäger (ed.), Republik und Dritte Welt: Festschrift für Dieter Oberndörfer zum 65. Geburtstag, Paderborn, Schöningh, 223-30.

MISAK Cheryl, (2004a), Truth, Politics, Morality: Pragmatism and Deliberation, London, Routledge.

MISAK Cheryl, (2004b), Truth and the End of Inquiry: A Peircean Account of Truth, Oxford, Clarendon Press. 
PEIRCE Charles Sanders, (1884), "Small Differences of Sensation," in Memoirs of the National Academy of Sciences, 3 part 1, 73-83.

PEIRCE Charles Sanders, (1892), "Dmesis," in The Open Court, n²60 (vol. VI, 39), S. 3399-402; cited in: [https://arisbe.sitehost.iu.edu/menu/library/bycsp/dmesis/mesis.htm].

PEIRCE Charles Sanders, (1931-1958), The Collected Papers of C.S. Peirce, 8 vols, edited by C. Harsthorne, P. Weiss, \& A. Burks, Cambridge, Ma., Harvard University Press.

PEIRCE Charles Sanders, (1976), The New Elements of Mathematics, vol. IV, C. Eisele (ed.), The Hague/ Paris, Mouton.

PEIRCE Charles Sanders, (1998), The Essential Peirce, Selected Philosophical Writings, volume 2 (1893-1913), Peirce Edition Project, eds., introduction by Nathan Houser, Bloomington and Indianapolis, In., Indiana University Press.

PIETARINEN Ahti-Veikko, (2006), Signs of Logic, Heidelberg, Springer.

PRINZ Wolfgang, (2012), Open Minds: The Social Making of Agency and Intentionality, Boston, The MIT Press.

RILEY Gresham, (1974), “Peirce's Theory of Individuals,” in TCPS, vol. 10/3, 135-65.

ROBINS Richard, (1967), Annotated Catalogue of the Papers of Charles S. Peirce, Cambridge, Ma., University of Massachusetts Press.

STJERNFELT Frederik, (2014), Natural Propositions: The Actuality of Peirce's Doctrine of Dicisigns, Boston, Docent Press.

TOMASEllo Michael, (2009), Why We Cooperate, Cambridge, Ma., The MIT Press.

TOMASEllo Michael, (2019), Becoming Human: A Theory of Ontogeny, Cambridge, Ma., The Belknap Press of Harvard University Press.

WIDLOCK Thomas, (2017), Anthropology and the Economy of Sharing, London/New York, Routledge. WILSON Edward, (2012), The Social Conquest of Earth, New York, Liveright.

WILSON Edward, (2014), The Meaning of Human Existence, New York, Liveright.

DE WAAL Cornelis \& Krzysztof Piotr SKOWRONSKI, (2012), "Self-Control, Values and Moral Development: Peirce on the Value-driven Dynamics of Human Morality," in Id. (eds.), The Normative Thought of Charles S. Peirce, New York, Fordham University Press, 159-71.

WITTGENSTEIN Ludwig, (1970), Über Gewissheit, Frankfurt-a.-Main, Suhrkamp.

\section{NOTES}

1. Numbers prefixed by "MS" refer to the microfilm edition of the manuscripts of C.S. Peirce as listed in Robins (1967).

2. This is Cheryl J. Misak's approach in Misak (2004a) and in Misak (2004b).

3. In his 1893 Monist-paper "Evolutionary Love," EP 1: 352-71. "EP" refers to one of the two volumes of Peirce (1998).

4. In rejoinder to Carus's criticism, Peirce opts for a "social theory of reality" to be explained in terms of a "socialistic" or "agapastic" ontology (6.610) - The decimal notation, e.g. 6.610, refers to the sixth volume and the 610th section in Peirce (1931-1958). 
5. Originally published in: The Open Court, No. 260 (Vol. VI, 39), 1892, S. 3399-3402; cited in: [https://arisbe.sitehost.iu.edu/menu/library/bycsp/dmesis/mesis.htm].

6. "[...] there should be something like personal consciousness in bodies of men who are in intimate and intensely sympathetic communion. It is true that when the generalization of feeling has been carried so far as to include all within a person, a stopping-place, in a certain sense, has been attained; and further generalization will have a less lively character. But we must not think it will cease. Esprit de corps, national sentiment, sympathy, are no mere metaphors. None of us can fully realize what the minds of corporations are, any more than one of my brain cells can know what the whole brain is thinking." $(6.271,1892)$.

7. Cf.: "Common sense, which is the resultant of the traditional experience of mankind, witnesses unequivocally that the heart is more than the head, and is in fact everything in our highest concerns, thus agreeing with my unproved logical theorem; and those persons who think that sentiment has no part in common sense forget that the dicta of common sense are objective facts, not the way some dyspeptic may feel, but what the healthy, natural, normal democracy thinks." $(1.654,1898)$.

8. In 1902 he defines rhetoric as the discipline that studies "the general conditions of the reference of Symbols and other Signs to the Interpretants which they aim to determine" (2.93).

9. Ahti Pietarinen lists 24 pairs of concepts describing the dialogical positions, including "the utterer-the interpreter," "the assertor-the critic," "the ego-the non-ego" and "the interlocutorthe receiver" (Pietarinen 2006: 77-8).

10. The sequential combination of tokens (Peirce: replicas) used constitutes the content which the assertion conveys. For example, in uttering the sentence "Socrates is wise," "[...] it is not the two signs 'Socrates' and 'wise' that are connected, but the replicas of them used in the sentence. We do not say that '---- is wise' as a general sign, is connected specially with Socrates but only that it is so as here used." (Peirce 1976: 346; MS 517, 1904, 34).

11. "Our speech gets its meaning by our other actions." (Translated by H. Pape).

12. "I term those occasions or objects which are denoted by the indices the subjects of the assertion." (2.338).

13. This is Peirce's thesis that the icon-index connection is a semiotic device for information acquisition not restricted to language. How widespread this is and how many physiological and cultural forms such "natural proposition" may have is shown by Stjernfelt (2014).

14. "The real world cannot be distinguished from a fictitious world by any description. [...] It is true that no language (as far as I know) has any particular form of speech so show that the real world is spoken of. But that is not necessary, since tones and looks are sufficient to show when the speaker is in earnest. These tones and looks act upon the listener, and cause him to attend to realities. They are, therefore, the indices of the real word." (2.337).

15. "When a listener hears the term 'light,' he proceeds to create in his mind an image thereof, and goes through the very same process of thought which is attributed to the Elohim in the first chapter of the Genesis. 'And God said, Let there be light; and there was light. And God saw the light, that it was good,' - that is, that the light was, in fact, what was intended to be created. It amounted to saying 'that is light'! Until this process is performed, the name excites no meaning in the mind of the listener." (2.341).

16. "The ancient definition of an enthymeme was 'a rhetorical argumentation,' and this is generally set down as a second meaning of the word. But it comes to the same thing. By a rhetorical argumentation was meant one not depending upon logical necessity, but upon common knowledge as defining a sphere of possibility. Such an argument is rendered logical by adding as a premise that which it assumes as a leading principle." $(2.449, \mathrm{Fn} 1)$.

17. In a number of books and papers M. Tomasello from 1999 onwards leading up to Becoming Human: A Theory of Ontogeny, 2019, building e.g. in Why We Cooperate, 2009, on experimental results with apes and young children of his own research group, explained cooperation, human morality 
and culture, in terms of cognitive and interactive ability emerging from social relations. The sociobiologist E.O. Wilson in The Social Conquest of Earth, 2012, and in The Meaning of Human Existence, 2014, even argued that the evolutionary success of humans depends only on the ability to use social relations for their individual needs and interests. Wilson's thesis builds among others on the results of the anthropologist Sarah Blatter Hrdy's work who showed in Mother Nature: Maternal Instincts and How They Shape the Human Species, 1999, and in Mothers and Others: The Evolutionary Origins of Mutual Understanding, 2009. Hrdy showed that cooperative rearing enables humans cognitively to understand and use close relations to other humans, making all sorts of social and moral cooperative actions available for their way of life. In a strangely restricted way the success of human social relations is used in Y.N. Harari's Sapiens. A Brief History of Humankind, 2014: the secret of the victory of homo sapiens over all other primate species, including the Homo neanderthalensis, is according to Harari, the use of fictions to organize social groups larger than 150 individuals.

18. This is the thesis of S. Blatter Hrdy's "Cooperative Breeding Hypothesis" in Mother Nature (1999): Humans' social and emotional competence is developed fully only if not only mother and father but other people are sharing their life with a child, acting as "alloparents," as Blatter Hrdy calls it.

19. Marten develops his approach to practical and anthropological issues in a number of books and papers, in particular in Der menschliche Mensch: Abschied vom utopischen Denken, 1988, and in his book Lebenskunst, 1993.

20. Marten's claim that intentions and social agency presuppose and can be explained in terms of sharing one's life corresponds to a psychological theory developed by Prinz (2012).

21. Only events count as logical individuals. In MS 478 he argues that Philipp drunk and Philipp sober are states of the same individual person only because this acts as a law for sequences of events, controlling and unifying them. Cf. G. Riley (1974). Cf. also 3.93.

22. Cf. 7.21-48, first published in 1884 in "Memoirs of the National Academy of Sciences," 3 part 1, 73-83.

23. "We can admit no statement concerning what passes within us except as a hypothesis necessary to explain what takes place in what we commonly call the external world." (5.266).

24. Cf. Tomasello (2009).

25. I discuss the function of self-control in Peirce's approach both to ethics and reasoning in detail in de Waal \& Skowronski (2012).

26. Peirce's account of self-control provides us with a strategic model for the process of decisionmaking. Because it describes a fallible and open-ended way of addressing the question of whether my belief in an argument is well founded. I have to begin self-critical reasoning by looking at all the reasons that induced me to accept an argument. However, although "reasoning is essentially thought under self-control" (1.606) and all development of thought is dialogical (4.551), selfcontrol can "never be perfectly thorough. For the last act of criticism is always itself open to further inquiry." (M 831, p. 12).

27. This life-sharing approach to politics is outlined in Marten (1994).

28. In his latest book Anthropology and the Economy of Sharing, 2017.

29. Indeed, as Widlok notes, this is what has happened time and again when sharing economies made contact with market economies.

30. What are sometimes seen as examples of a sharing economy, Uber and AirBnB, are only varieties of market economy.

31. Research on economic behavior, such as the experiments of Dan Ariely described in his Predictably Irrational, 2008, have shown that market exchange and human relations based on equal sharing not only exclude each other but that the first tends to destroy the later, if e.g. a price is introduced for acts of sharing. 


\section{ABSTRACTS}

In this paper I argue that a strong concept of sharing - a close interactive relation that preconsciously allows humans to grasp themselves and each other as human - is crucial for the human form of life. This concept of sharing is used to reconstruct some of Peirce's insights. Sharing is no part of Peirce's account of person, morality and interpersonal relations. But his rhetorical analysis of assertion as close, indexical interaction shows that sharing is necessary in semiotics and pragmatism. The concept of sharing is used to reconstruct his metaphysics of evolutionary agape love and sympathetic relations as a selection principle of commonly pursued purposes. Finally, sharing is shown to have economic meaning: the form of life in which humans may satisfy their needs may consist in sharing directly the necessities of life with each other. If humans live together and develop projects and purposes with one another because they share with one another what is here and now, democracy is needed: as the only form of government that allows for free and equal participation of the people.

\section{AUTHOR}

\section{HELMUT PAPE}

Otto-Friedrich-Universität Bamberg

helmut_pape[at]web.de 